\title{
The Effects of Higher Modes on the Response Modification Factor of Tall RC Buildings
}

\author{
Elham Rafiei ${ }^{1 *}$, Fakhreddin Ahmadi Danesh ${ }^{1}$, Fatemeh Matou ${ }^{1}$, Mahsa Shamsaei ${ }^{2}$ \\ ${ }^{1}$ Faculty of Earthquake Engineering, Department of Civil Engineering, \\ Khajeh Nasir Toosi University of Technology, Tehran, Iran \\ ${ }^{2}$ Faculty of Civil Engineering, Semnan University, Semnan, Iran
}

\begin{abstract}
The current seismic design procedures in the codes are typically based on the linear analysis and the first vibration mode. There are no specific recommendations to consider the effects of the higher modes contribution on the seismic behavior of tall buildings. Thus, by designing these structures and using the proposed codes behavior factor, the result of nonlinear analysis might be different. The purpose of this study is to consider the effects of higher modes on the strength reduction factor. In this regard, five special RC shear wall moment-resisting frame structures with 5, 12, 18, 30 and 50 stories were designed and modeled by PERFORM3D software. In order to consider the influence of higher modes, a single-run story shear-based adaptive pushover (SSAP) was selected to achieve capacity curve. The empirical strength reduction factor of each frame was calculated based on the capacity curve. In addition,the strength reduction factor of the frames obtained from nonlinear dynamic analysis and compared to those of SSAP and the code one. It was conclude that the $R$ value recommended by codes is incompatible for tall buildings and it should be modified for tall structures.
\end{abstract}

Keywords: pushover curve, behavior factor, strength reduction factor, ductility, over-strength, SSAP analysis, concrete moment frame with shear wall.

\section{Introduction}

The tendency to construct tall structures in seismic regions due to the development of analysis methods and construction technologies is increasingly becoming widespread. These structures have brought specific challengeable issues in accepted principals and criteria. It is considered that tall buildings have particular characteristics that warrant special consideration (Tuan, 2008). The dynamic response of the tall building is influenced by multiple modes of vibration more than the low-rise buildings(Maffei \& Yuen, 2007; Pennucci, Sullivan, \& Calvi, 2012).

Seismic codes consider a reduction in design loads for conventional force-based seismic design procedure by the strength reduction factor which reduces the linear elastic response spectra to the inelastic spectra (Lee, $\mathrm{Yu}, \&$ Tung, 2006). Many researchers have discussed the evaluation of strength reduction factor. For example,(Lai \& Biggs, 1980; Newmark \& Hall, 1973) focused on the effects of the different frequencies regions on the strength reduction factor. Furthermore, the studies focusing on the influence of soil conditions and the hypocenter of the earthquake on the strength reduction factor can be found in (Elghadamsi \& Mohraz, 1987; Hidalgo \& Arias, 1990; Miranda, 1993; Nassar \& Krawinkler, 1991; Riddell, 1995). Low cycle fatigue criteria were also addressed by (Costa, Romão, \& Oliveira, 2010). Although these studies evaluated the strength reduction factor in the single degree of freedom systems, there are some comprehensive research for multidegree of freedom systems. (Hwang \& Jaw, 1989; Takada, Hwang, \& Shinozuka, 1988) proposed some factors related to ductility to adjust the response modification factor. Additionally,the specific strength reduction factor, a function of ductility for steel frame, was calculated by (Costa et al., 2010; Kurban \& Topkaya, 2009; Lee et al., 2006). (Thuat, 2014) recognized that for a certain range of periods, the mean strength reduction factor demands are larger than the corresponding target ductility demands. Furthermore,(Akbari \& Maheri, 2013; Jorjani, 2009) found the fact that the height of the frame has a profound effect on the behavior factor, as it directly has an influence on the ductility capacity. It was also demonstrated that the response modification factors of steel structures equipped with viscous damper device are higher than those steel structures without damper device (Abdi et al., 2015).Another study (Sharifi, S. \& Toopchi-Nezhad, H., 2018) determined the response modification factor of medium moment-resisting RC frame at two different ductility levels, ordinary and spatial frames, and with a different number of bays.

Recently, there have been several studies taking into account the effects of the fundamental period and higher modes on seismic behavior of the structures. The spectrum given in seismic design codes were firstly modified by (Krawinkler \& Nassar, 1992), based on a function of the fundamental period in the different region of frequencies. Moreover, the effects of higher modes on the elastic analysis were investigated by (Daneshjoo \& Gerami, 2003). Additionally, (Hancilar, 2010) realized the fact that the inter-story drift in the upper level of high rise buildings is significantly influenced by the effect of higher modes. To predict the higher mode 
response,(Pennucci et al., 2012) proposed "substitute structure method"based on the equivalent linearization concept. (Izadinia, Rahgozar, \& Mohammadrezaei, 2012) compared different types of pushover methods to consider the effects of higher modes. A new modal pushover method was also proposed by (Shakeri, Shayanfar, \& Kabeyasawa, 2010).

Regarding the lack of recommendation for considering the effect of higher modes for tall buildings in the codes, the present work investigated a series of response modification factor of the $\mathrm{RC}$ shear wall-moment frame for several frames with a different number of stories. Accordingly, a specific nonlinear static method which considered the higher modes and nonlinear dynamic analyses was performed for five RC shear wallmoment frames. The obtained result showed that the response modification factor of the frames decreased as the number of stories increased.

\section{Response modification factor}

In the equivalent static method,the response modification factor, $\mathrm{R}$, is conveniently used to reduce the actual seismic forces to the design forces. Therefore, the structures will experience large inelastic deformation to dissipate the earthquake energy(Izadinia et al., 2012). The response modification factor is considered to be generally defined by over-strength and the ductility factors. These two factors were formed based on the fact that structures have significant reserve strength (over-strength) and capacity to dissipate energy (ductility)(Asgarian \& Shokrgozar, 2009). The response modification factor or strength reduction factor is influenced by structural properties such as ductility demand, damping ratio, fundamental period of vibration, soil properties and the characteristics of the earthquake ground motion(Lee et al., 2006). It can be obtained directly from the following formula using the above three components,

$$
R=R_{\mu} \cdot R_{s} \cdot Y
$$

in which $R_{\mu}, R_{S}$ and $Y$ is the ductility reduction factor, the overstrength factor and termed the allowable stress factor, respectively. As it is shown in Figure 1, which displays the actual force-displacement response curve idealized by a bilinear elastic-perfectly plastic response curve, these three parameters defined as:

$$
R_{\mu}=\frac{V_{e}}{V_{y}}, \quad R_{s}=\frac{V_{y}}{V_{s}}, \quad Y=\frac{V_{s}}{V_{w}}
$$

The bi-linearization of the baseshear vs. roof displacement (pushover) plot in this paper is based on the FEMA356 recommendation, considering equalareas under the actual and the bilinear curves in which the initial slope of the bilinear curve must intersect the actual curve at $60 \%$ of the distance to the yield point.

\section{Design of models}

The structural models considered in this study were five special RC shear wall moment-resisting frame structures having five, twelve, eighteen, thirty and fifty stories with different member configurations and properties to illustrate an extensive range of various fundamental periods and higher modes contributions. All these symmetric frames are $13 \mathrm{~m}$ wide which consist of three different bays as shown in Table 1 and the same story height which were demonstrated in Figure2. Each frame is regular in plan and in elevation with the same inter-story height equal to $3 \mathrm{~m}$ for all. The diaphragm is assumed to be rigid in the plane.Therefore, the displacements of the frame and wall are the same for a given story level. The buildings sites were assumed to be in Tehran, Iran, which is located at the first most seismically intensive zone.

Firstly, RC structural members were designed utilizing a standard force-based design of the structure on the basis of the linear analysis values and considering the R factor selected established on the 2800 Iranian Standard provision $3^{\text {rd }}$ edition (Standard, 2005), which was proposed 11 for dual system comprise to concrete special moment frame and concrete special shear wall. In terms of materials, in order to acquire sections with high ductility based on provision's limitations, three various classes of concrete for frames with a different number of stories and a class of steel were selected, as shown in Table 2. For the nonlinear analysis, mean values of material strength were considered and inelastic properties in bending were assigned.

Additionally, the stiffness of RC members wasdecreased due to various factors such as flexural and shear cracked, partial reinforcement slip, aggregate interlock, etc. Consequently, the effective stiffness must have been considered using codes recommendation. Table 3 illustrates the initial stiffness which was recommended by (FEMA., 2000) to consider the effects of concrete cracking in flexural stiffness. Moreover, the gravity loads were calculated based on the Ninth Issue of the National Building Regulations [30] and summarized in Table 4. It should be noted that all the frames were designed on the basis of the weak beam-strong column principle to prevent inelastic instability of the building. Both equivalent static and spectral dynamic analysis were conducted to control the story drifts.

Subsequently,Perform3D program was utilized to carry out nonlinear pushover analysis to achieve the capacity curve in order to calculate the $\mathrm{R}$ factor for each frame with different load patterns based on the number of vibration modes. 


\subsection{Modeling frame}

Evaluated frames in this study consist of beams, columns and shear wall. Each of these components modeled nonlinearly in PERFORM 3D as describes in following.

\subsubsection{Beams}

The RC beams were modeled with chord rotation element which consists of two symmetric FEMA beam components with specific nonlinear properties and two end rigid zone at the end of the element. Tri-linear F-D relationship with strength loss was used for FEMA beam components. The deformation capacities for these components were in terms of element end rotations. As shown in Figure 3 the beams end rotation corresponding to ultimate strength point $(\mathrm{U})$ and the point which is so large to introduce the stop point $(\mathrm{X})$ calculated 0.01 and 0.05 respectively. As regards beams can yield in bending, deformation $\mathrm{D} / \mathrm{C}$ ratio was used for the end rotation which was defined corresponding to ductile point and residual point equal 0.025 and 0.042 . In addition, the end moment at yield $(\mathrm{Y})$ and ultimate point $(\mathrm{U})$ were expressed as follows:

$$
\begin{gathered}
\boldsymbol{M}_{\boldsymbol{Y}}=\boldsymbol{f}^{\prime}{ }_{s} \boldsymbol{A}^{\prime}{ }_{S}\left(\boldsymbol{d}-\boldsymbol{d}^{\prime}\right)(3) \\
M_{U}=0.85 f_{c} b a\left(d-\frac{a}{2}\right)+f^{\prime}{ }_{S} A_{S}^{\prime}\left(d-d^{\prime}\right)(4)
\end{gathered}
$$

\subsubsection{Columns}

The RC columns were modeled as beams by chord rotation elements;nevertheless, FEMA columns components consider elastic-perfectly plastic. Furthermore, to take into account the interaction between axial force $(\mathrm{P})$ and the bending moment $(\mathrm{M})$, the P-M strength interaction surface for the column section was defined by a simple model as shown in Figure 4.

\subsubsection{Shear wall}

The shear walls have been modeled using fiber cross sections in which the nonlinear properties are represented by four different types of material; non-buckling inelastic steel, confined concrete, unconfined concrete and inelastic shear material as described in Table5. A summary of the beams, columns and shear walls cross section in 5 different frames mentioned are given in Table 6.

\subsection{Dynamic characteristic}

A two-dimensional finite element model of five mentioned frames was established for numerical analysis. The fundamental periods of the models are varied from $0.43 \mathrm{~s}$ in 5 -story model to $6.12 \mathrm{~s}$ in the 50 -story model. The modal participation ratio for each mode and the cumulative modal participation mass ratios can be defined followingEq. 5 and 6, respectively.

$$
\begin{aligned}
\varphi_{i} & =\frac{\eta_{i}}{\sum_{j=1} \eta_{j}} \\
\psi_{i} & =\frac{\sum_{j=1}^{i} m_{j}}{\sum_{t=1}^{n} m_{t}}
\end{aligned}
$$

, in which $\mathrm{m}$ is the effective mass participating the dynamic response of each mode, and the modal participation coefficient for each mode, $\eta_{\mathrm{i}}$, can be expressed as:

$$
\eta_{j i}=\frac{\left[E_{i}\right][M]\left[u_{j}\right]}{\left[u_{j}\right]^{T}[M]\left[u_{j}\right]}
$$

, where $[\mathrm{M}]$ is the mass matrices, $[\mathrm{u}]$ is the vibration mode vector of the structure, and $[\mathrm{E}]$ is the uniform matrix. The modal participation ratios and the cumulative modal participation mass ratios of the modes with most contribution were reported in Table 7. As expected, by increasing the number of stories, the number of the effective modes becomes more and the increase of fundamental period of vibration of the frame is well marked. This indicates the importance of higher modes in tall buildings.

\section{Analysis procedure}

Nonlinear static analysis with considering the effects of higher modes and nonlinear dynamic analysis were performed to calculate the response modification factor of five specific frames.

\subsection{The nonlinear static analysis}

The nonlinear static procedure or pushover analysis is increasingly used to establish the estimations of seismic demands for building structures. In the conventional pushover analysis, a constant lateral force pattern is monotonically subjected to the structural model which was under gravity loads until a predetermined target displacement is reached. However, none of the invariant force distributions can take into account the contribution of higher modes, which are significantly important in high rise buildings. Thus, numerous researchers have been focusing on considering the higher modes in pushover analysis. During past years, multimode pushover (MMP) method, modal pushover analysis (MPA), pushover results combination (PRC), 
incremental response spectrum analysis (IRSA), upper-bound pushover analysis, modified modal pushover analysis (MMPA), adaptive modal combination (AMC) (Poursha, Khoshnoudian, \& Moghadam, 2011) and single-run adaptive pushover procedure (Shakeri et al., 2010) were proposed to consider the effects of higher modes. In this study, to take into consideration the effects of higher modes, the single-run adaptive pushover procedure developed by Shakeri et al. was chosen to achieve capacity curve.

The single-run story shear-based adaptive pushover (SSAP) method considers the contribution of the instantaneous higher modes. The modal combination concept was used to define the load pattern rather than to combine the nonlinear responses due to each mode. At each analysis step, based on the instantaneous modal properties, the story shears associated with each considered mode are calculated by Eq. (8) and (9)(see Figure 1a and b). The story shears associated with each mode are combined using the SRSS rule (Eq. (10)); this is defined as the combined modal story shear (see Figure1c). In the calculation of the story shears for each mode using $E q$. (9), the sign reversal effects of the modal forces in the upper stories are considered. The lateral forces required to generate the combined modal story shears profile are assumed as the lateral load pattern. The required story forces are calculated by subtracting the combined modal shear of consecutive stories using Eq. (11)(see Figure 1d). The lateral load pattern is normalized with respect to its total value by $E q$. (12). The incrementally applied load profile at each step is then computed by $E q$. (13) [25].

$$
\begin{aligned}
& F_{i j}=\frac{\sum_{i=1}^{n} m_{i} \Psi_{i j}}{\sum_{i=1}^{n} \boldsymbol{m}_{i} \Psi_{i j}^{2}} \Psi_{i j} \boldsymbol{m}_{i} S a_{j}(8) \\
& \boldsymbol{V}_{\boldsymbol{i j}}=\sum_{\boldsymbol{k}=\boldsymbol{i}}^{\boldsymbol{n}} \boldsymbol{F}_{\boldsymbol{k} \boldsymbol{j}} \text { (9) } \\
& V_{i}=\sqrt{\sum_{j=1}^{m} V_{i j}^{2}}(10) \\
& \left\{\begin{array}{c}
F_{n}=V_{n} \\
F_{i}=V_{i}-V_{i+1} \quad i=1,2, \ldots,(n-1)
\end{array}\right. \\
& \overline{\boldsymbol{F}}_{\boldsymbol{i}}=\frac{\boldsymbol{F}_{i}}{\sum \boldsymbol{F}_{\boldsymbol{i}}}(12) \\
& \Delta \boldsymbol{F}_{\boldsymbol{i}}=\Delta \boldsymbol{V}_{\boldsymbol{b}} \times \overline{\boldsymbol{F}_{\boldsymbol{i}}}(13)
\end{aligned}
$$

where $\mathrm{i}$ is the story number, $\mathrm{j}$ : the mode number, $\psi_{\mathrm{ij}}$ : the $\mathrm{i}$-th component of the $\mathrm{j}$-th eigenvector (mode shape), $m_{i}$ : the mass of the $\mathrm{i}$-th story, $\mathrm{Sa}_{\mathrm{j}}$ : the spectral acceleration corresponding to the $\mathrm{j}$-th mode, $\mathrm{V}_{\mathrm{ij}}$ : the story shear in level $\mathrm{i}$ associated with mode $\mathrm{j}, \mathrm{V}_{\mathrm{i}}$ : the modal story shear in level $\mathrm{i}$ associated with all the considered modes. $\Delta \mathrm{V}_{\mathrm{b}}$ is the incremental base shear, $\Delta \mathrm{F}_{\mathrm{i}}$ : the ith component of the incremental applied load at each step.

\subsubsection{Nonlinear static pushover analysis}

In order to compute the strength reduction factor with considering the higher modes contribution and corresponding idealized bi-linearization capacity curve, two types of nonlinear pushover analyses were performed at horizontal load steps equal to $2 \%$ of the design capacity by Perform3D software. Firstly, the conventional pushover analysis was carried out with two different load distribution based on codes recommendation following as Eq. 14 and 15 . Furthermore, the SSAP pushover method was executed which is described in section 3. The lateral load patterns used in SSAP method were generated based on the vibration modes separately which reported at Table 7 and combination of mentioned modes sequentially. Thus, several load patterns were used to conduct the nonlinear pushover analysis for each frame. Additionally the numerical results of conventional pushover analysis which is not able to take into account the higher modes of contribution and SSAP with considering the modes were compared.

$$
\begin{aligned}
F_{i} & =V \frac{W_{i}}{\sum_{j=1}^{n} W_{j}} \\
F_{i} & =V \frac{W_{i} \times h_{i}}{\sum_{j=1}^{n} W_{j} \times h_{j}}
\end{aligned}
$$

\subsection{Nonlinear time history analysis}

Nonlinear time history analyses were carried out for seven real earthquake far field recordings, considering a soil type B, listed in Table 8. Firstly, the spectrum accelerations of seven records were normalized to their PGA and then scaled such that the mean value in the interval between $0.2 \mathrm{~T}$ and $1.5 \mathrm{~T}$, in which $\mathrm{T}$ is the fundamental period of the frame, are higher than 1.4 multiple design spectrum according to 2800 Iranian Standard provision $3^{\text {rd }}$ edition. Furthermore, the damping ratio of the models was assumed to be $5 \%$ for all vibration modes.

To determine the response modification factor under earthquake records, the IDA analysis needs to be established whereby the PGA value constantly increased until the collapse occurred. A series of nonlinear dynamic analyses were conducted instead of IDA analysis, in which for each frame, the PGA incrementally increased in order to specify yield and collapse points. The PGA and the base shear correspond to these points were used following the $E q$. 16to determine the R factor. 
Thus, the nonlinear dynamic analysis was carried out for 12, 30 and 50-story frames including seven records with an extra range of PGA. It was assumed that the yield point for the frame occurred when the first element reached IO performance level and the collapse point took place as the first element meet CP performance level or the story drift reach 0.02 and 0.025 for frames with five or fewer stories and more than five stories, respectively. For each frame, the PGA corresponds exactly to yield and collapse points and the base shear related them were extracted for each record and reported in Tables 12 to 14 with the empirical R-value.

$$
R=\frac{P G A_{\text {collapse }}}{P G A_{\text {yield }}} \times \frac{V_{\text {collapse }}}{V_{\text {yield }}}
$$

\section{Analytical results}

In this study, the response modification factor was investigated through nonlinear static and dynamic analysis of five concrete frames with 5,12,18, 30 and 50 stories which have shear wall-moment frame seismicforce-resisting system.

\subsection{Nonlinear Static Analysis}

To calculate empirical strength reduction factor based on the result of SSPA analysis, the forcedisplacement relationship is shown in Figure 5 for each frame and it was calculated according to section 2.

\subsubsection{Force-Displacement}

The capacity curve of each of four RC frames is shown in Figure 5 in which the horizontal axis represents the roof displacement and the vertical axis denotes the base shear of the frame. The pushover curves obtained based on the codes are shown as solid lines, where the dotted lines refer to the capacity curves correspond to SSAP result for the first vibration mode and the contribution of effective modes.

By comparing, the curves corresponding to the first mode and multi modes for 5 and 18 frames were set between triangular and uniform pushover curves shows the fact that the codes recommendation for the capacity of the low to medium rise frames are relatively conformed to the real one. Nevertheless, the capacity of the 30 and 50 story frames, which categorized as the tall frame, are significantly correlated with the capacity curves of vibration modes. As shown in Figure 5, the pushover curve of tall frames for combined effective modes are not identical to the code ones while the curve of the first mode is close to them.

\subsubsection{Response modification factor}

The response modification factor is to represent the design ductility level assigned for the entire structure. On the other hand, the inter-story drift is one of the collapse parameters that controls the response of buildings designed to modern seismic codes(Akbari \& Maheri, 2013). As lined in 2800 Iranian Standard recommendations for structures with fundamental periods equal $0.7 \mathrm{~s}$ or more, the ultimate capacity of the frames were assumed to have been reached when the global drift equal $2 \%$ of height of the frame. Afterwards, the maximum allowable drift specified 0.02 and the analysis stops when the largest controlled drift exceeds the maximum allowable drift.

Tables 9 and 10 report the over-strength and ductility reduction factor from five SSAP pushover analyses based on the first, two, three, four and eight vibration modes for 5, 12, 18, 30 and 50 story frames. The allowable stress factor according to the 2800 Iranian Standard (Standard, 2005)was assumed to be 1.5 for all frames in each analysis.

Table 9 shows that the overstrength factor $(\Omega)$ decreased $2 \%$ by the contribution of two first modes in the 5 story frame and eight modes in 50 story frame. Nevertheless, this reduction reached $10 \%$ for 12 and 18 -story frame and $3 \%$ for the 30 story frame, which were affected by eight modes. On the other hand, it was obvious that by increasing the number of stories from five to fifty, the overstrength factor correspond with the first mode decreased 13, 17, 28 and $34 \%$ in 12, 18, 30 and 50-story, respectively. These values reached 17, 23, 28 and $33 \%$ by the contribution of two modes, and 20,23, 29 and $34 \%$ by the effect of eight modes.

Moreover, it can be observed from Table 10 that although the ductility reduction factor $(\mathrm{R} \mu)$ increased $0.5 \%$ in the 5-story frame by the contribution of higher modes, it significantly decreased up to $6,8,10$ and $11 \%$ in 12 , 18,30 and 50-story frame. In addition, by increasing the number of stories from 5 to $12,18,30$ and 50 -story the $\mathrm{R} \mu$ corresponding to the first mode significantly decreased to 9, 28, 35 and 38\% respectively. Also, these values constantly increased to $15,33,44$ and $44 \%$ by considering the contribution of eight modes.

The value of response modification factor $(\mathrm{R})$ for the 5,12,18, 30 and 50-story frame corresponding to the first, two, three, four and eight modes are listed in Table 11. As mentioned, the R-value proposed by 2800 Iranian Standard (Standard, 2005) for the evaluated seismic system in this study is 11. By comparing the empirical R-value from analysis with the R-value related to code it can be observed that although the Rvaluecorresponds with the first mode for the 5-story frame is almost close to the code one, for other study frames it significantly reduced $\% 20, \% 40, \% 53$ and $59 \%$ in relation to R equal 11 according to code for 12,18 , 30 and 50-story frame, respectively. Furthermore, these reduction values remarkably increased to $28,46,57$ and $61 \%$ by considering two modes and $33,48,59$ and $62 \%$ by taking to account eight vibration modes. On the other hand, regarding the R-value corresponding the first mode, by considering the influence of higher modes it 
reduced $1 \%$ for 5 -story, $16 \%$ for 12,18 and 30 -story and $10 \%$ for the 50 -story frame. Although the effect of the first mode is considerably more significant than the combination of higher modes, the influence of higher modes cannot be neglected.

\subsubsection{Nonlinear time history analysis}

The response modification factor which was determined based on time history analysis was represented by Tables 12 to 14. As it can be observed, the average R-value from seven records was decreased by increasing the number of study.

\subsubsection{Inter-story Drift}

One of the most important parameters to evaluate the seismic behavior of frames is inter-story drift. Therefore, in this study, this parameter was calculated for all five frames under the effect of one mode and the contribution of predominant ones through pushover analysis.

Figure 6 shows the drift ratio of the 5-story RC shear wall frame after the application of two different load patterns; they were formed based on the first dominated mode and the combination of effective modes. It was shown that for both load patterns, in this frame, the maximum drift happened in the roof. It also indicates that the higher modes slightly affected the inter-story drift of the upper story.

With reference to Figure 7, the 12-story frame and also the 18-story frame were found to possess the maximum drift ratio in the middle stories. By comparing these results with those shown in Figure 5, it can be seen that by increasing the number of stories the maximum drift shifted from upper part of the frame to the middle height. This is more evident from Figure 8, which illustrates the story drift of the 30 and 50-story frames.

The effect of the contribution of higher modes is stronger in the upper height of the 12 and 18-story frame. In these frames, the value of drift ratio increased by $14 \%$ in the roof. However, Figure 8 shows that the middle height of the tall frame was considerably affected by higher modes. In contrast to the 12 and 18-story frames, the inter-story drift of high rise frames declined sharply in middle stories. Apart from small increase in the first seven stories and the last three ones in the 30-story frame and first ten levels and the last 12 ones in 50-story frame, the inter-story drift of other levels declined sharply and the maximum decrease took place in the 16th to the 20 th level to just $14 \%$ in the former one and in the 18 th to 28 th level to around $15 \%$ in the latter one.

\section{Discussion}

A general observation can be made from the results, represented by Tables 9, 10 and 11. As (Akbari \&Maheri, 2013; Mondal, Ghosh, \& Reddy, 2013) investigated that the overstrength component comparatively affected by the number of stories for steel X-braced RC frames and RC frames, this factor was significantly reduced by increasing the number of stories under each load distribution pattern in this study for RC shear wallframe models. By considering the contribution of higher modes, it can be also observed that the influence of the higher modes in 12, 18 and 30-story frame are higher than the 5 and 50-story frame. Moreover, it can be observed from Table 10 that the ductility reduction factor, $\mathrm{R} \mu$, for 5 story frame with increasing the number of higher modes appear to be of a lower order when compared with the taller study frames. Nevertheless, for 12 , 18,30 and 50 story frames the $\mathrm{R} \mu$ significantly depend on the higher modes. Additionally, the dependence of $\mathrm{R}_{\mu}$ on the higher modes becomes more by increasing the number of stories.

The empirical R-value which was extracted from SSAP procedure and nonlinear dynamic analysis shown the fact that the R-value decreased by increasing the number of stories. The number of stories has considerable influence on the ductility level and the R-value. Also, the effect of higher modes causes the R-value decline in tall frames. It might be concerned to the lower ductility of the elements in tall buildings. Although most codes consider the type of the seismic system and soil to specify the R-value, the effects of the modal period which are related to the height of the structure were ignored.

The influence of higher modes on the inter-story drift of high rise frame was considerable in middle of the frames and it causes the reduction of the drift which is closer to ones that came from the time history analysis.

\section{Conclusion}

In this study, the nonlinear static analysis was carried out based on the consideration of the instantaneous higher modes by a single-run story shear-based adaptive pushover (SSAP) method. Also, the nonlinear dynamic analysis was performed. The results lead to the following conclusion:

- The effect of the contribution of instantaneous higher modes on the dynamic behavior of tall frames is strong.

- Although the capacity curve obtained from conventional pushover analysis with codes load patterns have a complete coincidence with the curve established by SSAP for short story frame, they were clearly different for tall frames.

- The influence of higher modes causes higher ductility in middle stories and it leads to the reduction of story drift in mid-height of frames.

- By increasing the number of stories, the overall ductility of frames decreased. 
- The empirical R-value for tall buildings was gradually decreased by increasing the number of stories.

- The R-value recommended by codes is incompatible for tall buildings and it should be modified for tall structures.

\section{References}

[1] Abdi, H., Hejazi, F., Saifulnaz, R., Karim, I. A., \& Jaafar, M. S. (2015). "Response modification factor for steel structure equipped with viscous damper device". International Journal of Steel Structures, 15(3), 605-622.

[2] Akbari, R., \& Maheri, M. R. (2013), “ Analytical investigation of response modification (behaviour) factor, R, for reinforced concrete frames rehabilitated by steel chevron bracing," Structure and Infrastructure Engineering, 9(6), 507-515.

[3] Asgarian, B., \& Shokrgozar, H. (2009), "BRBF response modification factor," Journal of Constructional Steel Research, 65(2), 290298.

[4] Costa, A., Romão, X., \& Oliveira, C. S. (2010), “A methodology for the probabilistic assessment of behaviour factors," Bulletin of Earthquake Engineering, 8(1), 47-64.

[5] Daneshjoo, F., \& Gerami, M. (2003), "Higher mode effects on the seismic behavior of MDOF steel moment resisting frames," Journal of Seismology and Earthquake Engineering, 5(3), 41.

[6] Elghadamsi, F., \& Mohraz, B. (1987), "Inelastic earthquake spectra," Earthquake engineering \& structural dynamics, 15(1), 91-104.

[7] FEMA., E. U. F. E. M. A. (2000), "Prestandard and commentary for the seismic rehabilitation of buildings: FEMA. ,"

[8] Hancilar, U. C.., E. (2010). "Nonlinear response of high -rise buildings with respect to strong ground motion characteristics," The 14 ECEE.

[9] Hidalgo, P., \& Arias, A. (1990), "New Chilean code for earthquake-resistant design of buildings," Paper presented at the Proceedings 4th US National Conference on Earthquake Engineering.

[10] Hwang, H. H., \& Jaw, J.-W. (1989), "Statistical evaluation of response modification factors for reinforced concrete structures," National Center for Earthquake Engineering Research Buffalo, New York.

[11] Izadinia, M., Rahgozar, M. A., \& Mohammadrezaei, O. (2012), "Response modification factor for steel moment-resisting frames by different pushover analysis methods," Journal of Constructional Steel Research, 79, 83-90.

[12] Jorjani, A. (2009), "Parametric study of tall buildings with different lateral system," Master Thesis, Sharif University of Technology.

[13] Krawinkler, H., \& Nassar, A. A. (1992), "Seismic design based on ductility and cumulative damage demands and capacities," Nonlinear seismic analysis and design of reinforced concrete buildings, 23-39.

[14] Kurban, C. O., \& Topkaya, C. (2009), A numerical study on response modification, overstrength, and displacement amplification factors for steel plate shear wall systems," Earthquake engineering \& structural dynamics, 38(4), 497-516.

[15] Lai, S.-S. P., \& Biggs, J. M. (1980), "Inelastic response spectra for aseismic building design," Journal of the Structural Division, 106(6), 1295-1310.

[16] Lee, W.-H., Yu, C.-C., \& Tung, S. (2006), "A displacement-based strength reduction factor for high-rise steel moment-resisting frames," The Structural Design of Tall and Special Buildings, 15(3), 233-247.

[17] Maffei, J., \& Yuen, N. (2007), "Seismic performance and design requirements for high rise buildings," Structure Magazine, 28-32.

[18] Miranda, E. (1993), "Site-dependent strength-reduction factors," Journal of Structural Engineering, 119(12), 3503-3519.

[19] Mondal, A., Ghosh, S., \& Reddy, G. (2013), "Performance-based evaluation of the response reduction factor for ductile RC frames," Engineering Structures, 56, 1808-1819.

[20] Nassar, A. A., \& Krawinkler, H. (1991), "Seismic demands for SDOF and MDOF systems," John A. Blume Earthquake Engineering Center, Department of Civil Engineering, Stanford University.

[21] Newmark, N. M., \& Hall, W. J. (1973), "Procedures and criteria for earthquake-resistant design," Paper presented at the Selected Papers By Nathan M. Newmark: Civil Engineering Classics.

[22] Pennucci, D., Sullivan, T., \& Calvi, G. (2012), "Prediction of Higher-Mode Response of Tall RC Wall Buildings," Paper presented at the Proceedings of the 15th World Conference on Earthquake Engineering, Lisbon, Portugal.

[23] Poursha, M., Khoshnoudian, F., \& Moghadam, A. (2011), "A consecutive modal pushover procedure for nonlinear static analysis of one-way unsymmetric-plan tall building structures," Engineering Structures, 33(9), 2417-2434.

[24] Riddell, R. (1995), "Inelastic design spectra accounting for soil conditions," Earthquake engineering \& structural dynamics, 24(11), 1491-1510.

[25] Shakeri, K., Shayanfar, M. A., \& Kabeyasawa, T. (2010), "A story shear-based adaptive pushover procedure for estimating seismic demands of buildings," Engineering Structures, 32(1), 174-183.

[26] Sharifi, S., \& Toopchi-Nezhad, H. (2018). "Seismic response modification factor of RC-frame structures based on limit state design", International Journal of Civil Engineering, 1-16.

[27] Standard. (2005), 2800-05. Iranian code of practice for seismic-resistant design of buildings,” Third Revision, Building and Housing Research Center, Tehran, Iran.

[28] Takada, T., Hwang, H., \& Shinozuka, M. (1988), "Response modification factor for multiple-degree-of-freedom systems," Paper presented at the Proceedings.

[29] Thuat, D. V. (2014), "Strength reduction factor demands for building structures under different seismic levels," The Structural Design of Tall and Special Buildings, 23(1), 42-53.

[30] Tuan, H. P. (2008), "Seismic design considerations for tall buildings," MS thesis, ROSE School, Pavia, Italy. 


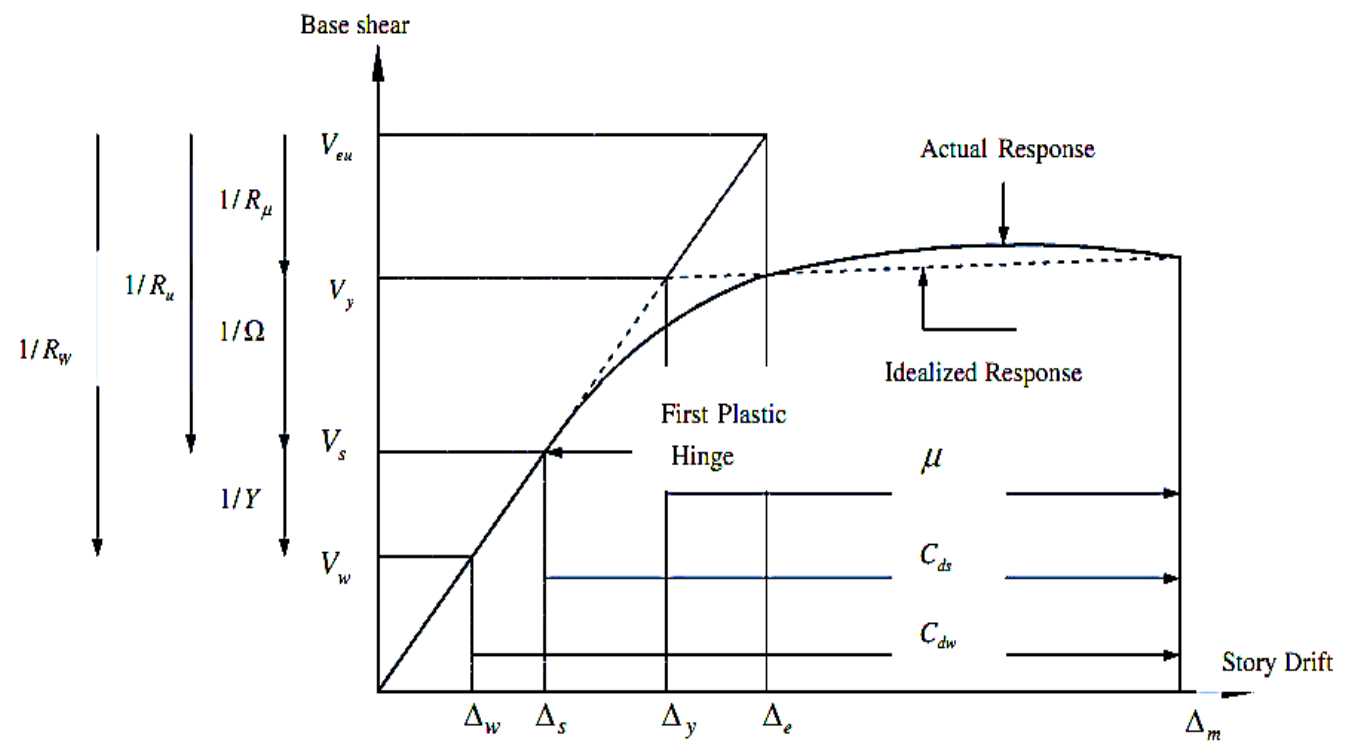

Figure 1. The capacity curve for a structure along with its bilinear idealization in pursuit of seismic demand parameters (Izadinia et al., 2012).

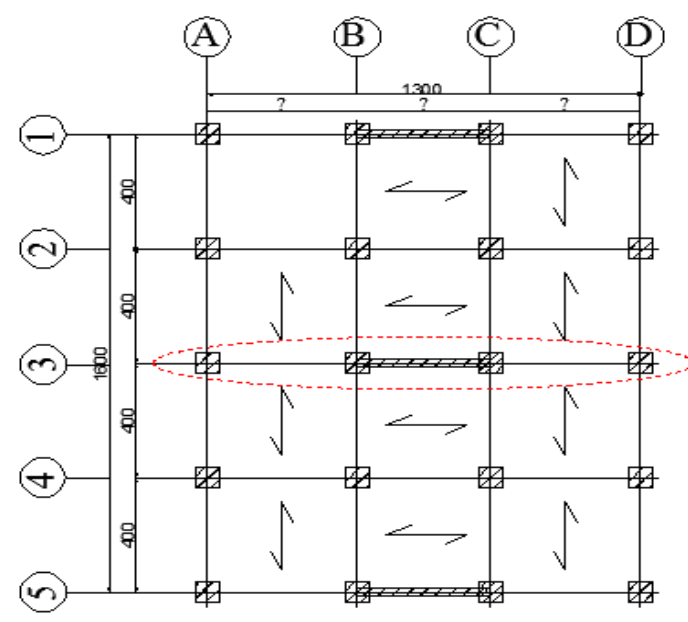

Figure 2. The models; a) five frames elevation, b) Plan 


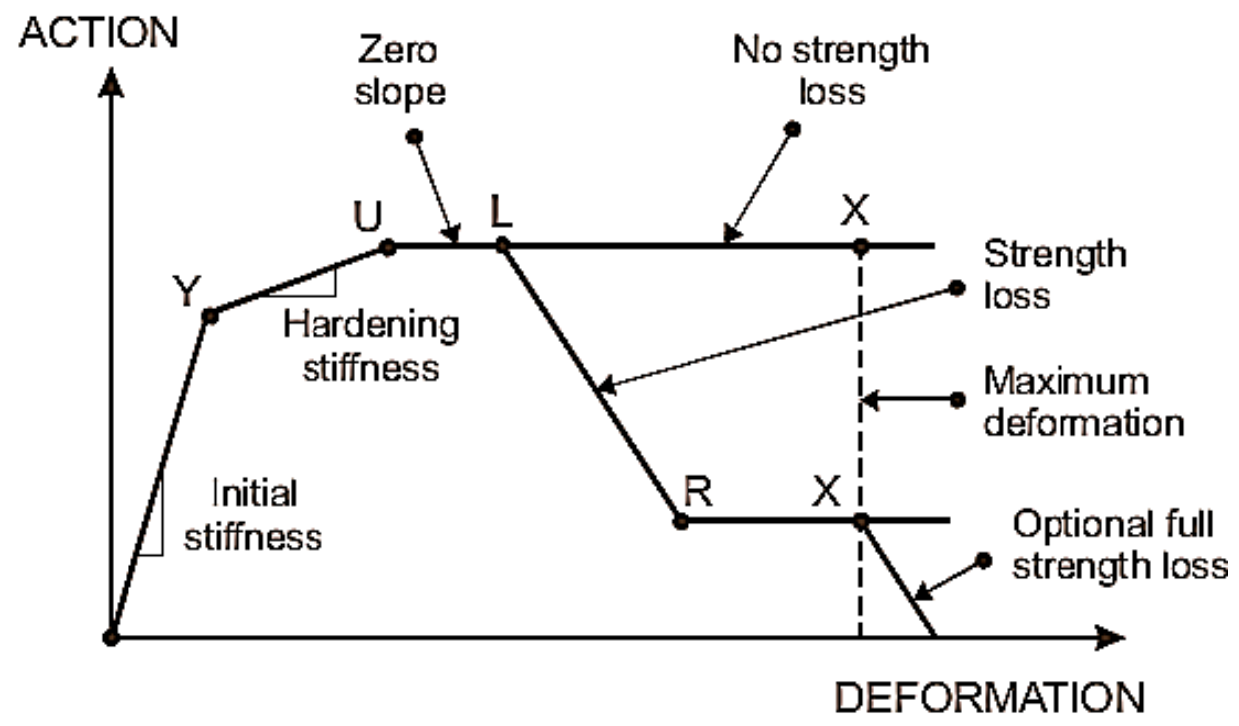

Figure 3. Perform Action-Deformation Relationship

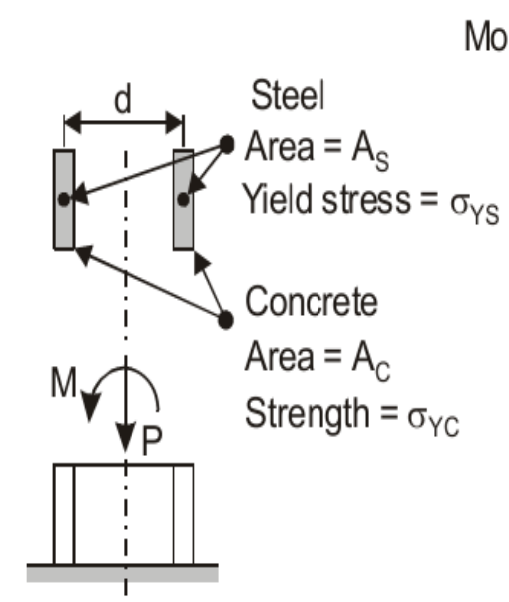

(a) Column Section and Loads
Moment at balance point $=0.5 A_{C} d \sigma_{Y C}+A_{S} d \sigma_{Y S}$

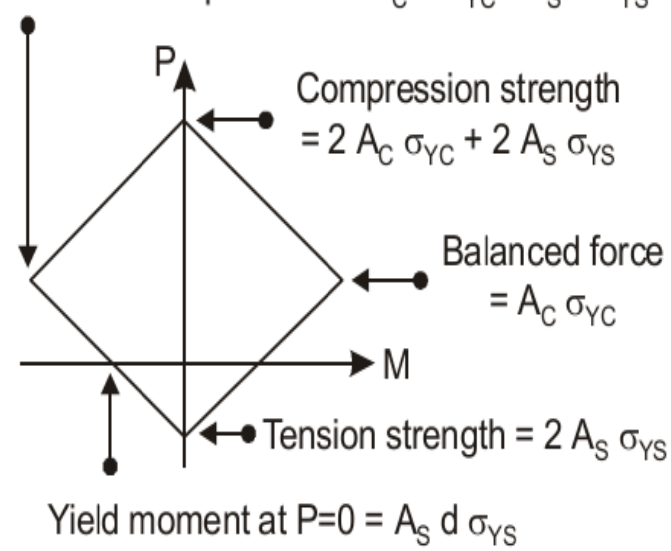

(b) Yield Surface

Figure 4. Simple Concrete Column 

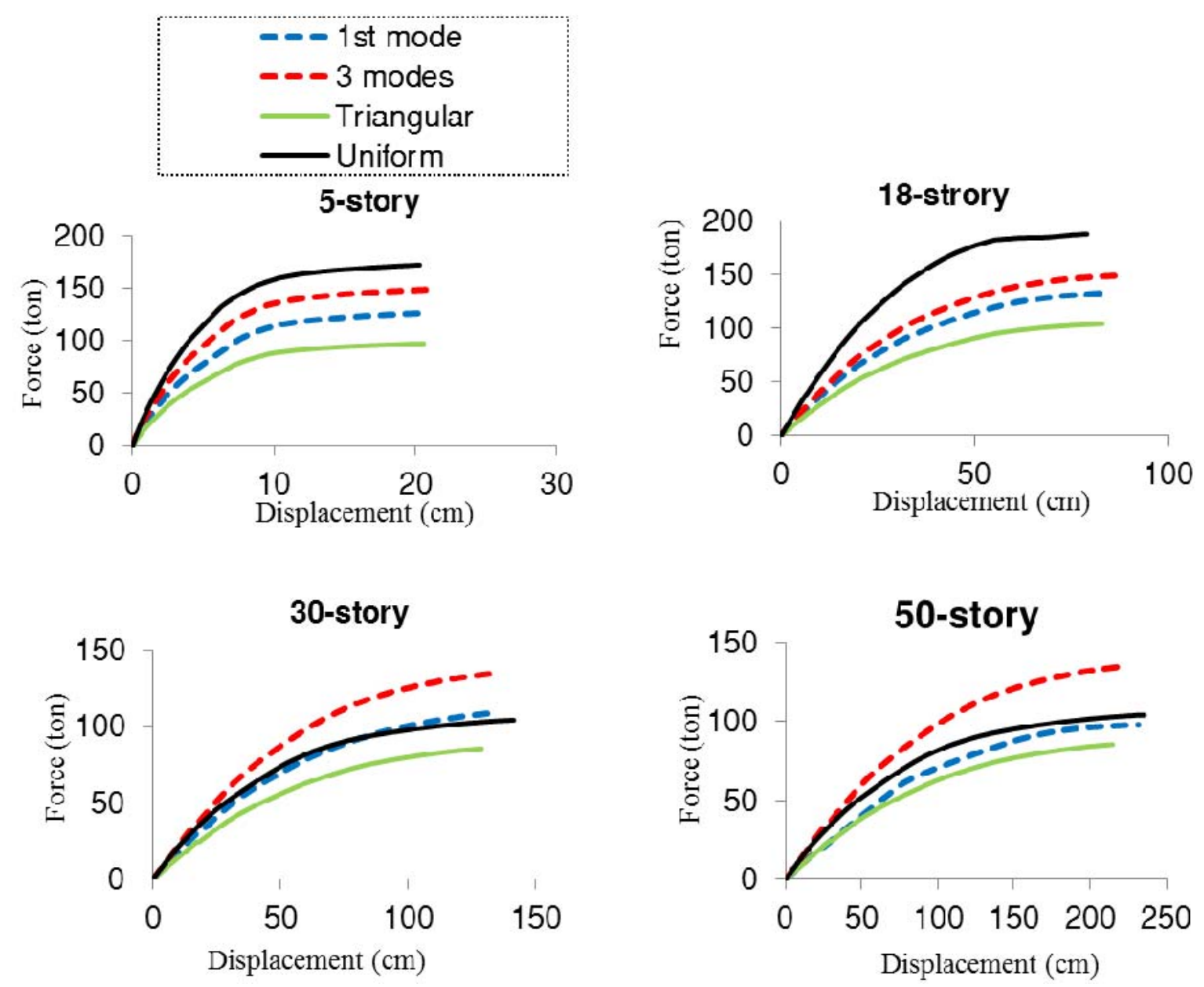

Figure 5. Force-Displacement relationship of 5, 18, 30 and 50-story frame under conventional and SSAP pushover method.

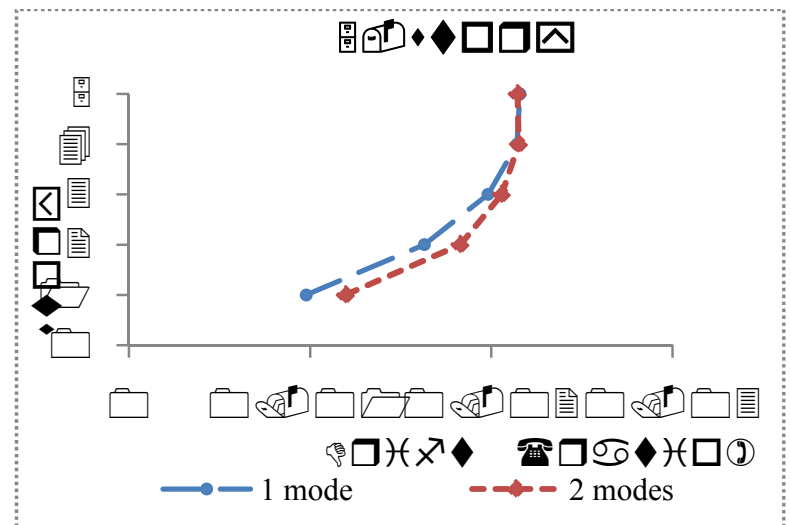

Figure 6. The inter-story drift of 5 story frame in the first mode of vibration and combined modes 

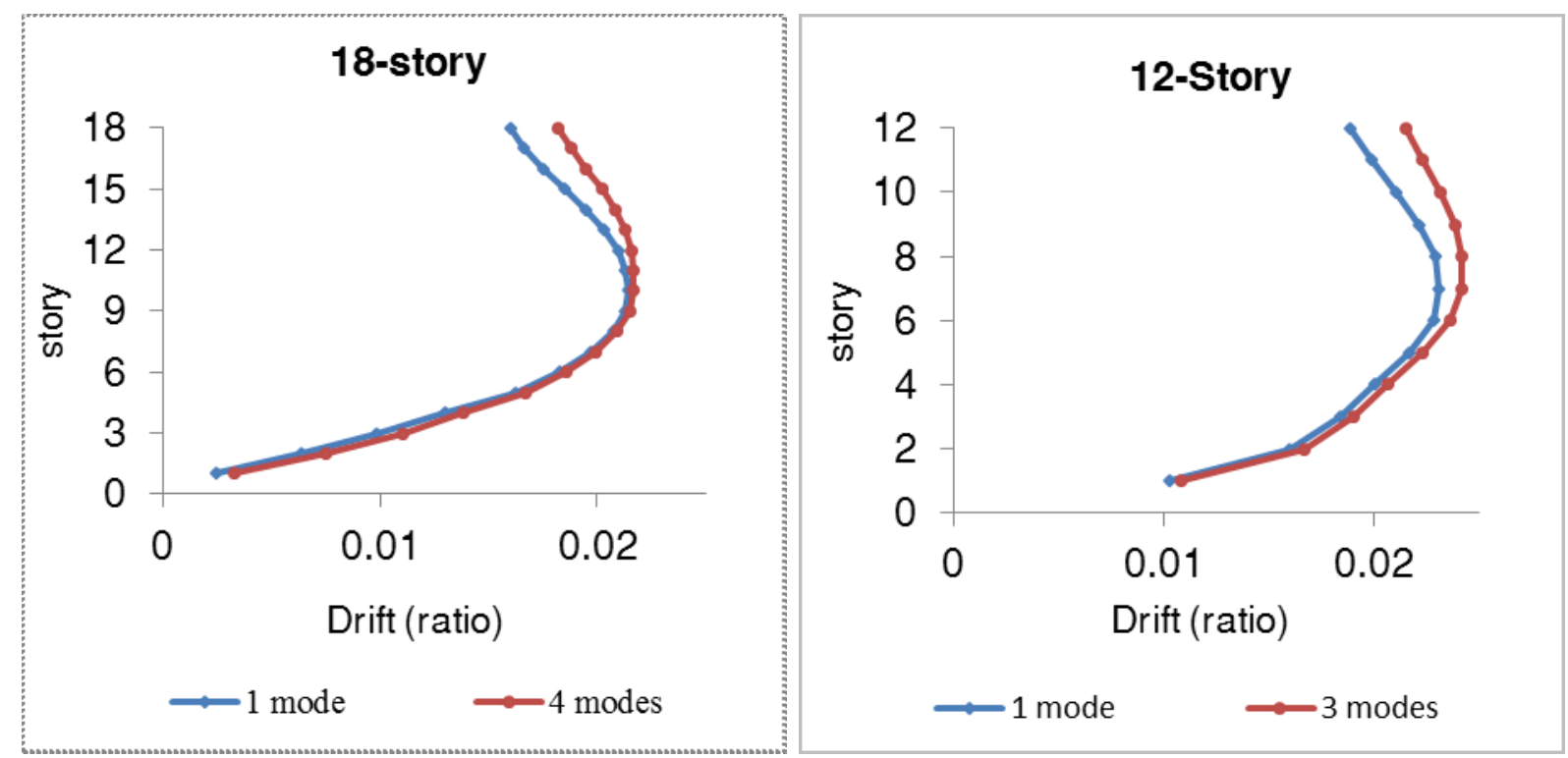

Figure 7. The inter-story drift of 12 and 18 story frames in the first mode of vibration and combined modes

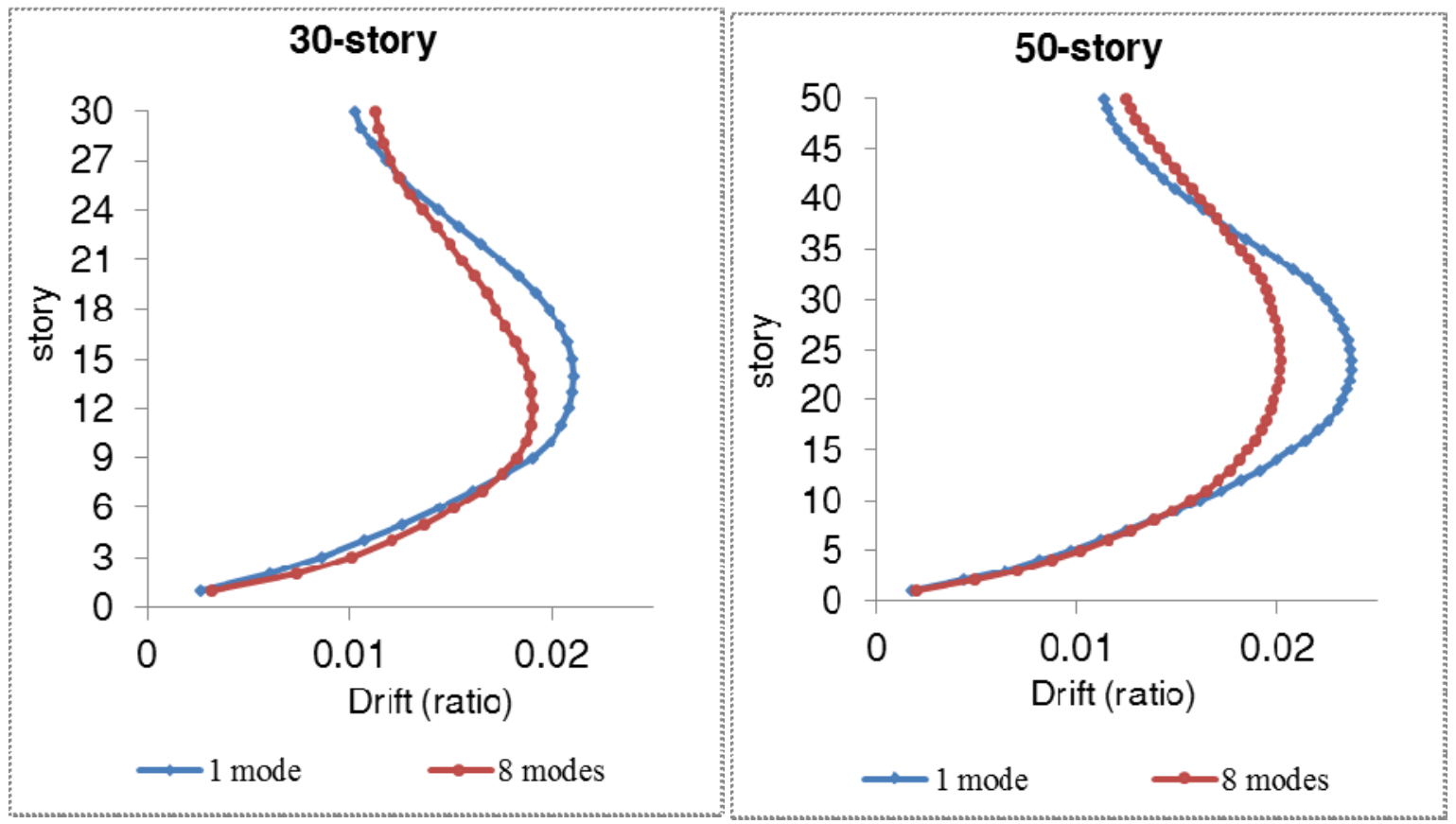

Figure 8 . The inter-story drift of 30 and 50 story frames in the first mode of vibration and combined modes

Table 1The length of each bays in five different models.

\begin{tabular}{cccc}
\hline \multirow{2}{*}{ Number of stories } & \multicolumn{3}{c}{ Bays $(\mathrm{m})$} \\
\cline { 2 - 4 } & left & median & right \\
\hline 5 & 5.0 & 3 & 5.0 \\
12 & 5.0 & 3 & 5.0 \\
18 & 4.5 & 4 & 4.5 \\
30 & 4.5 & 4 & 4.5 \\
50 & 4.0 & 5 & 4.0 \\
\hline
\end{tabular}


Table 2 Material properties

\begin{tabular}{ccc}
\hline Frames & Materials & Properties \\
\hline F5, F12, F18 & Concrete C25 & $F_{c u}=25 \mathrm{~N} / \mathrm{mm}^{2}$ \\
& $E=23 \mathrm{GPa}$ \\
& & Poisson's ratio, $v=0.2$ \\
F30 & $F_{c u}=30 \mathrm{~N} / \mathrm{mm}^{2}$ \\
& $E=27.4 \mathrm{GPa}$ \\
F40 & Poisson's ratio, $v=0.2$ \\
& & $F_{c u}=40 \mathrm{~N} / \mathrm{mm}^{2}$ \\
& & $E=31.6 \mathrm{GPa}$ \\
Cll frames & & Poisson's ratio, $v=0.2$ \\
& Steel reinforcement & $f_{y}=400 \mathrm{~N} / \mathrm{mm}^{2}$ \\
\hline
\end{tabular}

Table 3 Effective stiffness in thelinear design

\begin{tabular}{lc}
\hline Members & flexural stiffness \\
\hline Beams & $0.3 \mathrm{E}_{\mathrm{c}} \mathrm{I}_{\mathrm{g}}$ \\
Columns with design compressive axial load more than $0.5 \mathrm{~A}_{\mathrm{g}} \mathrm{f}_{\mathrm{c}}$ & $0.7 \mathrm{E}_{\mathrm{c}} \mathrm{I}_{\mathrm{g}}$ \\
Columns with design compressive axial load less than $0.1 \mathrm{~A}_{\mathrm{g}} \mathrm{f}_{\mathrm{c}}$ & $0.3 \mathrm{E}_{\mathrm{c}} \mathrm{I}_{\mathrm{g}}$ \\
No cracked wall & $0.8 \mathrm{E}_{\mathrm{c}} \mathrm{I}_{\mathrm{g}}$ \\
Cracked wall & $0.8 \mathrm{E}_{\mathrm{c}} \mathrm{I}_{\mathrm{g}}$ \\
\hline
\end{tabular}

Where $E_{c}$ is the modulus of elasticity of concrete and $I_{g}$ is the moment of inertia of the 'gross section

Table 4 Gravity load

\begin{tabular}{lcc} 
& Dead $\left(\mathrm{kg} / \mathrm{m}^{2}\right)$ & Live $\left(\mathrm{kg} / \mathrm{m}^{2}\right)$ \\
\hline Roof & 375 & 150 \\
Stories & 500 & 200 \\
\hline
\end{tabular}

Table 5 Inelastic properties of steel and concrete in shear walls

\begin{tabular}{lcccccccc}
\hline Material & FY & FU & DU & DX & E & DL & DR & FR/FU \\
\hline Non buckling inelastic steel & 340 & 500 & 0.01 & 0.025 & $2 \times 10^{5}$ & - & - & - \\
Confined concrete & 12.5 & 25 & 0.004 & 0.02 & 25000 & 0.0065 & 0.015 & 0.75 \\
& 15 & 30 & 0.004 & 0.02 & 27386 & 0.0065 & 0.015 & 0.75 \\
& 20 & 40 & 0.004 & 0.02 & 31625 & 0.0065 & 0.015 & 0.75 \\
Unconfined concrete & 12.5 & 25 & 0.0019 & 0.02 & 25000 & 0.0021 & 0.004 & 0.01 \\
& 15 & 30 & 0.0019 & 0.02 & 27386 & 0.0021 & 0.004 & 0.01 \\
& 20 & 40 & 0.0019 & 0.02 & 31625 & 0.0021 & 0.004 & 0.01 \\
\hline
\end{tabular}


Table 6 Cross sections in 5, 12, 18, 30 and 50 stories frames

\begin{tabular}{|c|c|c|c|c|c|c|c|c|}
\hline \multicolumn{5}{|c|}{ Walls } & \multicolumn{4}{|c|}{ Beams } \\
\hline \multirow{2}{*}{ Frame } & \multirow{2}{*}{ Story } & \multirow{2}{*}{ Thickness } & \multicolumn{2}{|c|}{ Rebar (\%) } & \multirow{2}{*}{ Frame } & \multirow{2}{*}{ Story } & \multirow{2}{*}{ Size (cm) } & \multirow{2}{*}{ Rebar } \\
\hline & & & flange & web & & & & \\
\hline \multirow[t]{3}{*}{5 story } & 1 & 15 & 0.045 & 0.007 & 5 story & $1-5$ & $25 \times 35$ & \\
\hline & 2 & 15 & 0.030 & 0.007 & 12 story & $1-12$ & $25 \times 35$ & \\
\hline & $3-5$ & 15 & 0.028 & 0.006 & 18 story & $1-18$ & $25 \times 35$ & \\
\hline \multirow[t]{4}{*}{12 story } & $1-4$ & 20 & 0.047 & 0.005 & 30 story & $1-30$ & $30 \times 40$ & \\
\hline & $5-6$ & 20 & 0.045 & 0.005 & 50 story & $1-50$ & $30 \times 50$ & \\
\hline & $7-8$ & 15 & 0.045 & 0.007 & \multicolumn{4}{|c|}{ Columns } \\
\hline & $9-12$ & 15 & 0.046 & 0.006 & Frame & Story & Size $(\mathbf{c m})$ & Rebar \\
\hline \multirow[t]{5}{*}{18 story } & 1 & 15 & 0.049 & 0.006 & 5 story & $1-5$ & $30 \times 30$ & $8 \phi 18$ \\
\hline & $2-3$ & 15 & 0.035 & 0.006 & 12 story & $1-2$ & $35 \times 35$ & $8 \phi 18$ \\
\hline & $4-7$ & 15 & 0.045 & 0.006 & & $3-12$ & $35 \times 35$ & $8 \phi 18$ \\
\hline & $8-10$ & 15 & 0.030 & 0.006 & 18 story & $1-4$ & $35 \times 35$ & $12 \phi 18$ \\
\hline & $11-18$ & 15 & 0.046 & 0.006 & & $5-9$ & $35 \times 35$ & $8 \phi 18$ \\
\hline \multirow[t]{8}{*}{30 story } & $1-3$ & 20 & 0.036 & 0.004 & & $10-18$ & $30 \times 30$ & $8 \phi 18$ \\
\hline & $4-5$ & 20 & 0.049 & 0.004 & 30 story & $1-6$ & $45 \times 45$ & $12 \phi 22$ \\
\hline & $6-7$ & 20 & 0.035 & 0.004 & & $7-11$ & $45 \times 45$ & $12 \phi 18$ \\
\hline & $8-11$ & 20 & 0.024 & 0.004 & & $12-14$ & $40 \times 40$ & $12 \phi 18$ \\
\hline & $12-14$ & 20 & 0.032 & 0.004 & & $15-19$ & $35 \times 35$ & $12 \phi 18$ \\
\hline & 15 & 20 & 0.045 & 0.004 & & $20-30$ & $30 \times 30$ & $8 \phi 18$ \\
\hline & $16-19$ & 15 & 0.045 & 0.006 & 50 story & $1-4$ & $55 \times 55$ & $16 \phi 26$ \\
\hline & $20-30$ & 15 & 0.046 & 0.006 & & $5-8$ & $50 \times 50$ & $16 \phi 26$ \\
\hline \multirow[t]{7}{*}{50 story } & $1-14$ & 20 & 0.036 & 0.004 & & $9-16$ & $50 \times 50$ & $16 \phi 22$ \\
\hline & $15-16$ & 20 & 0.049 & 0.004 & & $17-18$ & $45 \times 45$ & $12 \phi 26$ \\
\hline & $17-20$ & 20 & 0.035 & 0.004 & & $19-21$ & $45 \times 45$ & $12 \phi 22$ \\
\hline & $21-24$ & 15 & 0.035 & 0.006 & & $22-26$ & $45 \times 45$ & $12 \phi 18$ \\
\hline & $25-31$ & 15 & 0.032 & 0.006 & & $27-32$ & $40 \times 40$ & $12 \phi 18$ \\
\hline & $32-36$ & 15 & 0.030 & 0.006 & & $33-38$ & $35 \times 35$ & $8 \phi 18$ \\
\hline & $37-50$ & 15 & 0.046 & 0.006 & & $39-50$ & $30 \times 30$ & $8 \phi 18$ \\
\hline
\end{tabular}


Table 6 Dynamic characteristic of models

\begin{tabular}{|c|c|c|c|c|}
\hline Type of frame & Mode & Period(s) & $\begin{array}{c}\text { Modal participation } \\
\text { ratio }\end{array}$ & $\begin{array}{c}\text { Cumulative participation } \\
\text { mass ratio }\end{array}$ \\
\hline \multirow[t]{2}{*}{ 5-story } & 1 & 0.43 & 1 & 0.6810 \\
\hline & 2 & 0.09 & 0.5753 & 0.9064 \\
\hline \multirow[t]{3}{*}{ 12-story } & 1 & 1.51 & 1 & 0.6257 \\
\hline & 2 & 0.28 & 0.5675 & 0.8272 \\
\hline & 3 & 0.11 & 0.3460 & 0.9021 \\
\hline \multirow[t]{4}{*}{18 -story } & 1 & 2.02 & 1 & 0.6222 \\
\hline & 2 & 0.41 & 0.5548 & 0.8133 \\
\hline & 3 & 0.16 & 0.3524 & 0.8904 \\
\hline & 4 & 0.09 & 0.2499 & 0.9293 \\
\hline \multirow[t]{5}{*}{30 -story } & 1 & 3.66 & 1 & 0.6316 \\
\hline & 2 & 0.92 & 0.5065 & 0.7936 \\
\hline & 3 & 0.36 & 0.3366 & 0.8652 \\
\hline & 4 & 0.20 & 0.2518 & 0.9052 \\
\hline & 5 & 0.12 & 0.1939 & 0.9290 \\
\hline \multirow[t]{5}{*}{ 50-story } & 1 & 6.20 & 1 & 0.6068 \\
\hline & 2 & 1.55 & 0.5362 & 0.7813 \\
\hline & 3 & 0.67 & 0.3365 & 0.8500 \\
\hline & 4 & 0.37 & 0.2532 & 0.8889 \\
\hline & 5 & 0.23 & 0.2028 & 0.9139 \\
\hline
\end{tabular}

Table 7 Earthquakes included in the study of far-field ground motions

\begin{tabular}{ccccccc}
\hline No & Earthquake & Station & M & $\begin{array}{c}\text { Closest to fault } \\
\text { rupture(km) }\end{array}$ & PGA & $\begin{array}{c}\text { Epi-central } \\
\text { Distance(km) }\end{array}$ \\
\hline 1 & Imperial & Cerro Prieto & 6.53 & 26.5 & 0.176 & 24.82 \\
2 & Nolley & Castaic - Old Ridge Route & 6.69 & 22.6 & 0.490 & 40.68 \\
3 & Northridge & LA - 116th St School & 6.69 & 41.9 & 0.208 & 41.01 \\
4 & Northridge & LA - Obregon Park & 6.69 & 37.9 & 0.563 & 39.39 \\
5 & San Fernando & Lake Hughes \#12 & 6.61 & 20.3 & 0.330 & 20.04 \\
6 & Loma Prieta & $\begin{array}{c}\text { Anderson Dam } \\
\text { (Downstream) }\end{array}$ & 6.93 & 21.4 & 0.239 & 26.57 \\
7 & Victoria, & Cerro Prieto & 6.33 & 34.8 & 0.621 & 33.73 \\
\hline
\end{tabular}

Table 8 Over-strength factor $(\Omega)$

\begin{tabular}{cccccc}
\hline \multirow{2}{*}{ Frame } & \multicolumn{5}{c}{ Modes } \\
\cline { 2 - 6 } & first mode & 2 modes & 3 modes & 4 modes & $\mathbf{8}$ modes \\
\hline 5 story & 1.94 & 1.91 & 1.91 & 1.91 & 1.91 \\
12 story & 1.70 & 1.59 & 1.57 & 1.58 & 1.53 \\
18 story & 1.62 & 1.48 & 1.49 & 1.49 & 1.46 \\
30 story & 1.40 & 1.37 & 1.37 & 1.37 & 1.36 \\
50 story & 1.29 & 1.28 & 1.29 & 1.30 & 1.27 \\
\hline
\end{tabular}


Table 9 Ductility based force reduction factor $\left(\mathrm{R}_{\mu}\right)$

\begin{tabular}{cccccc}
\hline \multirow{2}{*}{ Frame } & \multicolumn{5}{c}{ Modes } \\
\cline { 2 - 6 } & first mode & 2 modes & 3 modes & 4 modes & 8 modes \\
\hline 5 story & 3.80 & 3.82 & 3.82 & 3.82 & 3.82 \\
12 story & 3.46 & 3.34 & 3.36 & 3.29 & 3.24 \\
18 story & 2.73 & 2.68 & 2.59 & 2.50 & 2.58 \\
30 story & 2.48 & 2.32 & 2.24 & 2.14 & 2.23 \\
50 story & 2.34 & 2.25 & 2.15 & 2.08 & 2.19 \\
\hline
\end{tabular}

Table 10 Response modification factor (R-factor)

\begin{tabular}{cccccc}
\hline \multirow{2}{*}{ Frame } & \multicolumn{5}{c}{ Modes } \\
\cline { 2 - 6 } & first mode & 2 modes & 3 modes & 4 modes & 8 modes \\
\hline 5 story & 11.10 & 10.97 & 10.95 & 10.95 & 10.95 \\
12 story & 8.82 & 7.95 & 7.92 & 7.82 & 7.42 \\
18 story & 6.66 & 5.95 & 5.79 & 5.59 & 5.67 \\
30 story & 5.21 & 4.79 & 4.61 & 4.40 & 4.55 \\
50 story & 4.52 & 4.33 & 4.14 & 4.06 & 4.15 \\
\hline
\end{tabular}

Table 11 The strength reduction factor for 12 story frame

\begin{tabular}{lccccccc}
\hline \multirow{2}{*}{ TH } & \multicolumn{2}{c}{ PGA } & \multicolumn{2}{c}{ Base Shear } & \multicolumn{2}{c}{ CP/IO } & \multirow{2}{*}{ R } \\
\cline { 2 - 6 } & IO-Beam & CP-Beam & IO-Beam & CP-Beam & PGA & Base Shear & \\
\hline Imperial & 1.985 & 11.4 & 60.3 & 215 & 5.74 & 3.57 & 20.48 \\
North1 & 0.84 & 2.27 & 83.12 & 139.3 & 2.70 & 1.68 & 4.53 \\
North2 & 2.8 & 9.75 & 62.85 & 207.2 & 3.48 & 3.30 & 11.48 \\
North3 & 1.86 & 7.3 & 87.5 & 244 & 3.92 & 2.79 & 10.94 \\
Sanfernando & 3.198 & 12.6 & 98.25 & 352 & 3.94 & 3.58 & 14.12 \\
LomaPrieta & 2.03 & 4.99 & 66.54 & 140.2 & 2.46 & 2.11 & 5.18 \\
Victoria & 0.58 & 3.13 & 61.5 & 144.7 & 5.40 & 2.35 & 12.70 \\
\hline Average & \multicolumn{7}{c}{} \\
\hline
\end{tabular}

Table 12 The strength reduction factor for 30 story frame

\begin{tabular}{|c|c|c|c|c|c|c|c|}
\hline \multirow[b]{2}{*}{ TH } & \multicolumn{2}{|c|}{ PGA } & \multicolumn{2}{|c|}{ Base Shear } & \multicolumn{2}{|c|}{ CP/IO } & \multirow[b]{2}{*}{$\mathbf{R}$} \\
\hline & $\begin{array}{c}\text { IO- } \\
\text { Beam }\end{array}$ & CP-Beam & IO-Beam & CP-Beam & PGA & Base Shear & \\
\hline Imperial & 4.22 & 11.52 & 114.6 & 300 & 2.73 & 2.62 & 7.15 \\
\hline North1 & 1.24 & 3 & 103.7 & 207.9 & 2.42 & 2.00 & 4.85 \\
\hline North2 & 4.81 & 12.45 & 132.2 & 292.2 & 2.59 & 2.21 & 5.72 \\
\hline North3 & 3.83 & 11.39 & 201.4 & 583 & 2.97 & 2.89 & 8.61 \\
\hline San Fernando & 6.86 & 24.55 & 231 & 966 & 3.58 & 4.18 & 14.97 \\
\hline Loma Prieta & 2.97 & 6.88 & 121.2 & 231.5 & 2.32 & 1.91 & 4.42 \\
\hline Victoria & 1.83 & 3.72 & 154.7 & 265 & 2.03 & 1.71 & 3.48 \\
\hline Average & & & & & & & 7.03 \\
\hline
\end{tabular}


Table 13 The strength reduction factor for 50 story frame

\begin{tabular}{lccccccc}
\hline \multirow{2}{*}{ TH } & \multicolumn{2}{c}{ PGA } & \multicolumn{2}{c}{ Base Shear } & \multicolumn{2}{c}{ CP/IO } & \multirow{2}{*}{$\mathbf{R}$} \\
\cline { 2 - 7 } & IO-Beam & CP-Beam & IO-Beam & CP-Beam & PGA & Base Shear & \\
\hline Imperial & 6.5 & 13.28 & 197.4 & 369.5 & 2.04 & 1.87 & 3.82 \\
North1 & 1.94 & 5.93 & 193.3 & 506.2 & 3.06 & 2.62 & 8.00 \\
North2 & 9.25 & 22 & 265 & 626.1 & 2.38 & 2.36 & 5.62 \\
North3 & 7.44 & 16.85 & 496.9 & 1156 & 2.26 & 2.33 & 5.27 \\
San Fernando & 17.2 & 36.1 & 878.9 & 1792 & 2.10 & 2.04 & 4.28 \\
Loma Prieta & 3.17 & 7.6 & 150.3 & 312.6 & 2.40 & 2.08 & 4.99 \\
Victoria & 2.36 & 5.46 & 198 & 433 & 2.31 & 2.19 & 5.06 \\
\hline Average & \multicolumn{7}{c}{} \\
\hline
\end{tabular}

